\title{
Dietary consumption of phytochemicals and breast cancer risk in Mexican women
}

\author{
Luisa Torres-Sanchez ${ }^{1}$, Marcia Galvan-Portillo', Mary S Wolff² and \\ Lizbeth Lopez-Carrillo ${ }^{1, *}$ \\ ${ }^{1}$ Instituto Nacional de Salud Pública, Av. Universidad No. 655, Col. Sta. María Ahuacatitlán, CP 62508, \\ Cuernavaca, Morelos, Mexico: ${ }^{2}$ Division of Environmental and Occupational Medicine, Department of \\ Community Medicine, Mount Sinai School of Medicine, Gustave L Levy Place, New York, NY 10029-6574, USA
}

Submitted 2 February 2007: Accepted 7 May 2008: First published online 23 July 2008

\begin{abstract}
Objective: To perform an evaluation of selected phytochemicals intake and breast cancer (BC) risk in Mexican women.

Design: We conducted hospital-based case-control study.

Setting: Mexico City between 1994 and 1996.

Subjects: A total of 141 histologically confirmed BC cases were age-matched $( \pm 3$ years) to an equal number of hospital controls. The reproductive history of each woman was obtained by direct interview. The dietary consumption of flavonols, flavones, flavan-3-ols, cinnamic acid, lariciresinol, pinoresinol, secoisolariciresinol, matairesinol and coumestrol was obtained by means of a validated FFQ.

Results: Among postmenopausal women, high dietary intake of flavonols and flavones was associated with a significant reduction of $\mathrm{BC}$ risk (high $v$. low tertile: $\mathrm{OR}=0 \cdot 21,95 \%$ CI $0 \cdot 07,0 \cdot 60, P$ for trend $=0 \cdot 004$ and OR $=0 \cdot 29,95 \%$ CI $0 \cdot 10$, $0 \cdot 82, P$ for trend $=0 \cdot 025$, respectively); consumption of lignans (lariciresinol and pinoresinol) showed a similar effect, but only among premenopausal women (high $v$. low tertile: $\mathrm{OR}=0 \cdot 32,95 \%$ CI $0 \cdot 10,0.99, P$ for trend $=0.051$ and OR $=0 \cdot 19,95 \%$ CI $0 \cdot 06,0 \cdot 62, P$ for trend $=0 \cdot 006$, respectively).

Conclusions: Our results support a protective role of specific dietary phytochemicals in $\mathrm{BC}$ risk by menopausal status, independent of other reproductive factors.
\end{abstract}

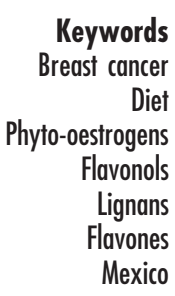

Phytochemicals are compounds present in plant-derived foods, including soya, grain cereals, seeds and berries, that can be grouped into families based upon similarities in chemical structure: flavonoids (isoflavones, flavones, flavonols, flavan-3-ols, flavanones and anthocyanins), dietary lignan precursors (secoisolariciresinol, matairesinol, lariciresinol and pinoresinol), cinnamic acid (quinnic acid and caffeine acid), and coumestans (coumestrol) ${ }^{(1)}$. All of the aforementioned compounds are polyphenols, which have antioxidant, antiproliferative and antiangiogenic biological activity. Some of these compounds have weak oestrogenic activity, which may confer a protective effect against breast cancer $(\mathrm{BC})^{(1,2)}$.

The incidence of $\mathrm{BC}$ worldwide is characterized by important geographical differences, which suggests that environmental factors, specifically diet, may play a role in its aetiology. This is consistent with the increased risk of $\mathrm{BC}$ reported for women emigrating from areas of low to high $\mathrm{BC}$ incidence ${ }^{(3)}$.

Both the consumption of soya ${ }^{(4,5)}$, a rich source of isoflavones, and the subsequent excretion of isoflavones have been associated with a decreased risk of BC among
Asian women ${ }^{(6,7)}$. Information regarding other phytochemicals consumed in Western countries is limited and inconsistent. In prospective studies conducted in Western populations, a beneficial effect has not been found for the consumption $^{(8-11)}$ or high urinary excretion ${ }^{(12)}$ of specific isoflavones and flavonols. In contrast, beneficial effects have been observed in retrospective studies measuring the consumption of flavones ${ }^{(13,14)}$, flavonols, flavones and flavan-3-ols ${ }^{(15)}$, as well as the intake ${ }^{(16)}$ and urinary excretion of daidzein and genistein ${ }^{(17)}$. Studies determining the protective effect of lignans (the phyto-oestrogens present in highest amounts in Western diets) have measured dietary consumption $^{(8,15,16,18)}$, serum concentration ${ }^{(19,20)}$ and urinary metabolites (enterolactone and enterodiol) ${ }^{(21)}$.

Dietary patterns in Mexico play a role in BC risk. Particularly the intake of lettuce, spinach, onion and citrus fruits $^{(22)}$, as well as vitamin E, polyunsaturated fat $^{(23)}$ and vitamin $\mathrm{B}^{(24)}$, are protective for $\mathrm{BC}$; in contrast, carbohydrate consumption is related to increased $\mathrm{BC}$ risk $^{(25)}$. Some of these foods (lettuce, onion, citrus fruits) contain phyto-oestrogens ${ }^{(26)}$. We extended these efforts by establishing a data set of phytochemical contents in 
Mexican foods, to perform an evaluation of the intake of selected phytochemicals and BC risk in Mexican women.

\section{Materials and methods}

The present study is a secondary analysis of a hospitalbased, case-control study evaluating the effect of exposure to DDT (dichlorodiphenyltrichloroethane) and its main metabolite, $p, p^{\prime}$-DDE (dichlorodiphenyldichloroethylene), on $\mathrm{BC}$ risk. It was conducted in three hospitals in Mexico City, Central Region of Mexico (National Institute of Cancer Research, General Hospital of Mexico and Hospital Manuel Gea González), between March 1994 and April 1996. A total of 141 BC cases were identified and age-matched $( \pm 3$ years) with 141 hospital controls. The inclusion criterion for all participants was a minimum of 20 years' residence in Mexico City ${ }^{(27)}$.

\section{Participants}

Cases were all women between 21 and 79 years of age, with a first-time diagnosis of histologically confirmed BC, who had received no previous cancer treatment. Tumour stage was classified using the tumour-nodes-metastasis system.

For each case, an age-matched ( \pm 3 years) female control with no mammary pathology was identified. Subject selection was carried out in all clinical services (except oncology) of participating hospitals. Principal diagnoses of control subjects were as follows: injuries $(17 \cdot 7 \%)$, genitourinary diseases $(14 \cdot 9 \%)$, gastrointestinal disorders $(11 \cdot 3 \%)$, ophthalmic diseases $(5 \cdot 6 \%)$, nonspecific pathologies $(4 \cdot 3 \%)$, blood disorders $(4 \cdot 2 \%)$, respiratory diseases $(3.6 \%)$, musculoskeletal and connective tissue disorders $(3.5 \%)$, disorders of the central nervous system $(2 \cdot 8 \%)$, dermatological diseases $(2 \cdot 8 \%)$, infectious diseases $(2 \cdot 7 \%)$, endocrine disorders $(2 \cdot 6 \%)$, CVD $(2 \cdot 6 \%)$ and auditory diseases $(2 \cdot 4 \%)$, with other diagnoses in smaller proportions.

Information was obtained from each participant regarding diet, sociodemographic characteristics, reproductive history and family antecedents of BC via a direct interview conducted in the hospital by trained interviewers, who knew the case-control status but not the study's hypothesis. Anthropometric measurements (weight and height) were collected at the time of the interview to calculate BMI. Participation rates among cases and controls were $81 \%$ and $72 \%$, respectively. All participants signed an informed consent letter.

\section{Dietary phytochemical consumption}

A semi-quantitative FFQ, previously updated and validated $^{(26)}$, was used to estimate the daily dietary consumption of phytochemicals. Cases were asked about dietary habits during the 12 -month period prior to the onset of symptoms, and controls were asked the same questions in reference to the 12 months before the interview. The intake of nutrients derived from the consumption of food and beverages was estimated by means of the Food Intake Analysis System 3.0 software (Texas University School of Public Health, Houston, TX, USA) ${ }^{(23,26)}$.

To estimate the dietary consumption of flavonols, flavan3-ols, flavones, cinnamic acid, lignans and coumestrol, we created a database using published nutritional data for the phytochemical content in ninety-five different foods ${ }^{(26)}$. The values of flavonols, flavan-3-ols, flavones and cinnamic acid were expressed in milligrams, while lignans (lariciresinol, pinoresinol, secoisolariciresinol and mataresinol) were in micrograms per $100 \mathrm{~g}$ of edible portion per day.

\section{Statistical analysis}

Reproductive and sociodemographic differences between cases and controls were evaluated using the $t$ test and $\chi^{2}$ statistic, while differences in the medians of macronutrient and phytochemical consumption were evaluated using a Mann-Whitney test. To determine the association between the dietary consumption of each phytochemical and the risk of $\mathrm{BC}$, we used tertiles based on the distribution in the control group. Odds ratios for the effect of phytochemicals on $\mathrm{BC}$ risk were calculated in the total population and stratified by menopausal status using unconditional logistic regression models.

The following known reproductive characteristics associated with BC were considered as potential confounders: age at menarche (years), four categories of parity and age at birth of first child $(\geq 3$ children and $<20$ years for first child, $<3$ children and $<20$ years for first child, $\geq 3$ children and $\geq 20$ years for first child, $<3$ children and $\geq 20$ years for first child, no children), lifetime lactation (months), family history of BC, alcohol consumption (yes/no) and BMI. Each one of them was added to the corresponding crude model, and those that changed the odds ratio by more than $10 \%$ were kept in the final multivariate model $^{(28)}$.

The dose-response relationship was evaluated by including the tertiles of each phytochemical in the model as an ordinal variable; additionally, interaction terms between menopausal status and phytochemicals were checked. We considered as statistically significant a $P$ value of $<0 \cdot 05$. The analysis was performed with the STATA 9.0 statistical software package (Stata Corporation, College Station, TX, USA).

\section{Results}

Compared with BC cases, controls were significantly younger at the birth of their first child, had more pregnancies and greater lifetime lactation. The proportion of women with a family history of $\mathrm{BC}$ and the average BMI were marginally smaller among controls than cases. 
No differences were found regarding the remainder of the variables included in Table 1 . Most of the breast tumours were stage II.
The median dietary consumption of macronutrients and selected phytochemicals, as well as the 10th and 90th percentiles, are presented in Table 2. Dietary consumption

Table 1 Selected characteristics of the study population: hospital-based, case-control study on intake of selected phytochemicals and breast cancer risk, Mexico City, 1994-1996

\begin{tabular}{|c|c|c|c|}
\hline Characteristic & Cases $(n 141)$ & Controls $(n 141)$ & $P$ value \\
\hline \multicolumn{4}{|l|}{ Age (years) } \\
\hline Mean & $49 \cdot 5$ & $48 \cdot 9$ & \multirow[t]{2}{*}{$0 \cdot 71 \ddagger$} \\
\hline SD & $14 \cdot 1$ & $13 \cdot 2$ & \\
\hline \multicolumn{4}{|c|}{ Age at menarche (years) } \\
\hline Mean & $13 \cdot 0$ & $13 \cdot 3$ & \multirow[t]{2}{*}{$0 \cdot 17 \ddagger$} \\
\hline SD & $1 \cdot 6$ & $1 \cdot 7$ & \\
\hline \multicolumn{4}{|c|}{ Age at birth of first child (years) } \\
\hline Mean & $22 \cdot 6$ & $20 \cdot 6$ & \multirow{2}{*}{$0.002 \ddagger$} \\
\hline SD & $5 \cdot 8$ & $4 \cdot 7$ & \\
\hline \multicolumn{4}{|c|}{ Parity (no. of children) } \\
\hline Mean & $3 \cdot 0$ & $4 \cdot 1$ & \multirow[t]{2}{*}{$0.000 \ddagger$} \\
\hline $\mathrm{SD}$ & $2 \cdot 7$ & $2 \cdot 9$ & \\
\hline \multicolumn{4}{|c|}{ Total accumulated lactation (months) } \\
\hline Mean & $20 \cdot 0$ & $36 \cdot 9$ & \multirow[t]{2}{*}{$0.001 \ddagger$} \\
\hline SD & $27 \cdot 9$ & $42 \cdot 9$ & \\
\hline \multicolumn{4}{|c|}{ Menopausal stage (\%) } \\
\hline Premenopausal & $49 \cdot 6$ & $48 \cdot 9$ & \multirow[t]{2}{*}{$0.902 \S$} \\
\hline Postmenopausal & $50 \cdot 3$ & $51 \cdot 1$ & \\
\hline \multicolumn{4}{|c|}{ Age at menopause (years) $t$} \\
\hline Mean & $44 \cdot 5$ & $44 \cdot 5$ & \multirow[t]{2}{*}{$0.99 \ddagger$} \\
\hline SD & $8 \cdot 4$ & $6 \cdot 3$ & \\
\hline \multicolumn{4}{|l|}{ BMI $\left(\mathrm{kg} / \mathrm{m}^{2}\right)$} \\
\hline Mean & $27 \cdot 3$ & $26 \cdot 4$ & \multirow[t]{2}{*}{$0 \cdot 07 \ddagger$} \\
\hline SD & $5 \cdot 2$ & $4 \cdot 6$ & \\
\hline \multicolumn{4}{|c|}{ Family history of breast cancer (\%) } \\
\hline Yes & $10 \cdot 9$ & $5 \cdot 1$ & $0.07 \S$ \\
\hline \multicolumn{4}{|c|}{ Alcohol consumption (\%) } \\
\hline Yes & $14 \cdot 5$ & $17 \cdot 1$ & $0.54 \S$ \\
\hline \multicolumn{4}{|l|}{ Tumour stage (\%) } \\
\hline I & $8 \cdot 5$ & & \\
\hline II & $78 \cdot 0$ & & \\
\hline III & $10 \cdot 6$ & & \\
\hline IV & $2 \cdot 8$ & & \\
\hline
\end{tabular}

†For postmenopausal women only.

$\ddagger P$ from $t$ test.

$\S P$ from $\chi^{2}$ test.

Table 2 Distribution of the daily consumption of nutrients and phytochemicals in the study population: hospital-based, case-control study on intake of selected phytochemicals and breast cancer risk, Mexico City, 1994-1996

\begin{tabular}{|c|c|c|c|c|c|c|}
\hline \multirow[b]{2}{*}{ Daily nutrient consumption } & \multicolumn{3}{|c|}{ Cases $(n 141)$} & \multicolumn{3}{|c|}{ Controls ( $n$ 141) } \\
\hline & 10th percentile & Median & 90th percentile & 10th percentile & Median & 90th percentile \\
\hline Energy (MJ) & $4 \cdot 90$ & $7 \cdot 88$ & $11 \cdot 76$ & $4 \cdot 76$ & $7 \cdot 52$ & $11 \cdot 48$ \\
\hline Energy (kcal) & $1171 \cdot 1$ & $1883 \cdot 2$ & $2808 \cdot 4$ & $1140 \cdot 6$ & $1795 \cdot 5$ & $2741 \cdot 8$ \\
\hline Carbohydrates (g) & $145 \cdot 5$ & $234 \cdot 3$ & $366 \cdot 0$ & $127 \cdot 8$ & $216 \cdot 1$ & $342 \cdot 1$ \\
\hline Proteins (g) & $38 \cdot 6$ & $62 \cdot 2$ & $93 \cdot 0$ & $36 \cdot 3$ & $60 \cdot 0$ & $92 \cdot 8$ \\
\hline Total fat $(\mathrm{g})$ & $50 \cdot 2$ & $81 \cdot 6$ & $125 \cdot 5$ & $52 \cdot 1$ & $83 \cdot 1$ & $123 \cdot 9$ \\
\hline Flavonolst (mg) & $14 \cdot 1$ & $27 \cdot 8^{\star *}$ & $44 \cdot 3$ & $16 \cdot 7$ & $31 \cdot 0$ & $46 \cdot 9$ \\
\hline Flavonesł (mg) & $0 \cdot 6$ & $2 \cdot 5^{\star}$ & $5 \cdot 5$ & 0.6 & $2 \cdot 6$ & $6 \cdot 0$ \\
\hline Flavan-3-ols (mg) & $1 \cdot 3$ & $7 \cdot 9$ & $21 \cdot 1$ & $2 \cdot 5$ & $8 \cdot 4$ & $21 \cdot 4$ \\
\hline Cinnamic acid (mg) & $56 \cdot 6$ & $127 \cdot 9$ & $227 \cdot 0$ & $53 \cdot 8$ & $115 \cdot 0$ & $219 \cdot 9$ \\
\hline Lariciresinol $(\mu \mathrm{g})$ & $74 \cdot 5$ & $148 \cdot 6$ & $352 \cdot 0$ & $83 \cdot 8$ & $149 \cdot 3$ & $354 \cdot 2$ \\
\hline Pinoresinol $(\mu \mathrm{g})$ & $30 \cdot 6$ & $60 \cdot 6$ & $153 \cdot 4$ & $31 \cdot 3$ & $60 \cdot 0$ & $129 \cdot 8$ \\
\hline Secoisolariciresinol $(\mu \mathrm{g})$ & $32 \cdot 3$ & $66 \cdot 3$ & $101 \cdot 9$ & $29 \cdot 6$ & $67 \cdot 5$ & $98 \cdot 3$ \\
\hline Matairesinol $(\mu \mathrm{g})$ & $0 \cdot 1$ & $0 \cdot 7$ & $2 \cdot 8$ & $0 \cdot 2$ & $0 \cdot 8$ & $2 \cdot 7$ \\
\hline Coumestrol (mg) & $0 \cdot 3$ & $1 \cdot 8$ & $2 \cdot 6$ & $0 \cdot 4$ & $1 \cdot 8$ & $2 \cdot 7$ \\
\hline
\end{tabular}

Median values were significantly different from those of the control group (Mann-Whitney test): ${ }^{*} P<0 \cdot 05,{ }^{\star \star} P<0 \cdot 01$.

tQuercetin, quercetin-3-rutinoside, free quercetin, quercetin-3-glucoside, quercetin-4-glucoside, quercetin-3,4-diglucoside, myricetin, kaempferol, conjugated isorhamnetin and isorhamnetin-4-glucoside.

‡Conjugated luteolin and apigenin. 
of flavonols $(31 \cdot 0 v 27 \cdot 8 \mathrm{mg} / \mathrm{d})$ and flavones $(2 \cdot 6 v$. $2.5 \mathrm{mg} / \mathrm{d}$ ) was significantly greater in controls than cases.

Postmenopausal women in the highest tertiles of flavonols and flavones consumption showed a statistically significant decrease in $\mathrm{BC}$ risk $(\mathrm{OR}=0 \cdot 21,95 \% \mathrm{CI} 0 \cdot 07$, $0 \cdot 60$ and $\mathrm{OR}=0 \cdot 29,95 \% \mathrm{CI} 0 \cdot 10,0 \cdot 82)$ compared with women in the lowest tertiles. In both cases the tests for trend were significant ( $P$ for trend $=0.004$ and 0.025 , respectively). Among premenopausal women, high consumption of the lignans lariciresinol and pinoresinol (high $v$. low tertile: $\mathrm{OR}=0 \cdot 32,95 \%$ CI $0 \cdot 10,0 \cdot 99, P$ for trend $=0 \cdot 051$ and $\mathrm{OR}=0 \cdot 19,95 \%$ CI $0 \cdot 06,0 \cdot 62, P$ for trend $=0 \cdot 006$, respectively) was associated with a significant reduction in $\mathrm{BC}$ risk (Table 3 ). There were no significant interactions between menopausal stage and phytochemical dietary consumption.

All previous results remained when $p, p^{\prime}$-DDE values were added in the models (data not shown).

\section{Discussion}

The present study is the first one conducted in a Mexican population about specific phytochemical intake and BC risk. Regarding the consumption of flavonoids, the inverse association between flavonols and flavones consumption and the risk of $\mathrm{BC}$ is consistent with previous studies conducted in Greece ${ }^{(13)}$, Italy ${ }^{(14)}$ and the USA ${ }^{(15)}$, which reduces the likelihood that our results may be due to chance. In the two first studies, a reduction in BC risk was associated with an increase in dietary flavones consumption, while in the last study risk reduction was associated with the consumption of flavonols, flavones, flavan-3-ols and lignans.

Additionally we showed a protective effect of lariciresinol and pinoresinol among premenopausal women. A recent study also found a similar effect among postmenopausal women with oestrogen receptor- and progesterone receptor-positive BC tumours ${ }^{(29)}$. This suggests that these compounds operate through an oestrogen antagonist mechanism ${ }^{(30)}$; however, further research is needed to reach a definite conclusion about the protective role of these phyto-oestrogens.

We also found in our study population that onion and hot sauce (made with tomatoes, onion and chilli pepper) are sources of flavonols and flavones, while banana, melon, lettuce and tomatoes contain lariciresinol and pinoresinol (data not shown). A previous study in Mexico showed a protective effect of $\mathrm{BC}$ due to onion consumption $^{(22)}$. Besides flavonoids and some antioxidants (e.g. $\mathrm{Se}^{(31)}$ and $\beta$-sitosterol ${ }^{(32)}$ ), onion is a source of lariciresinol and secoisolariciresinol ${ }^{(33)}$. To assess whether flavonoids or other compounds may be responsible for the favourable effect of onion in BC, a model adjusting by flavonol, lariciresinol and secoisolariciresinol intake (not included in the tables) was run. Results showed a significant, protective effect of onion intake among postmenopausal women $(\mathrm{OR}=0 \cdot 17, P$ for trend $=0 \cdot 02)$, suggesting that other compounds present in onion may also be exerting a protective role in $\mathrm{BC}$ risk. Thus, the phyto-oestrogen composition of Mexican foods deserves further attention to advance understanding of their role in breast carcinogenesis.

In addition to their antioxidant properties, antiangiogenic activity and apoptosis promotion, flavonoids exhibit an anticarcinogenic function by inhibiting enzymes that participate in cell differentiation and tumour growth (DNA topoisomerases and kinases) ${ }^{(34)}$. They also inhibit aromatases, which are involved in the synthesis of endogenous oestrogens ${ }^{(35)}$. Owing to either their aromatase inhibition activity or their competence as oestrogenic receptors, high circulating amounts of isoflavones have been negatively associated with serum oestrogen concentration $^{(36)}$.

Although lignans share the same hormonal and nonhormonal mechanisms as flavonoids, a modification of their protective effect has been observed depending on the oestrogen receptor status of mammary tissue. This suggests a hormone-independent mechanism ${ }^{(2,37)}$ such that mammary cells without oestrogen receptors are subject to apoptosis. This may explain the differential effect of pinoresinol and lariciresinol intake by menopausal status.

Some methodological considerations should be deliberated in the interpretation of our results. Our estimation of dietary flavonoids and lignans consumption using an FFQ should be taken into consideration with regard to its reproducibility/reliability. However, our instrument captures $18 \%$ and $47 \%$ of the actual daily dietary intake for flavan-3-ols and lariciresinol, respectively ${ }^{(26)}$. Thus, our results may be a conservative estimation of the actual effect of phytochemicals on BC risk. Regardless, there is little reason to suspect that such an underestimation could be differential in relation to cases and controls, because interviewers and participants were blinded to the study hypothesis.

On the other hand, we consider the possibility of a selection bias to be low, given that the consumption of macronutrients observed among our controls, compared with that reported in the National Survey of Nutrition of female residents of Mexico City ${ }^{(38)}$, was similar. Furthermore, the diagnoses of the clinical controls were not statistically related to consumption of the studied phytochemicals (data not shown), while other types of cancer were not included because of their potential relationship with phytochemical intake. Moreover, the rates of participation in our study were high (around 80\%), reducing the possibility that non-participating individuals differed substantially in dietary habits and other characteristics compared with participants.

No information was available for the present study regarding the use of oral contraceptives (OC) and hormone replacement therapy (HRT). Although national 
Dietary phytochemicals and breast cancer risk

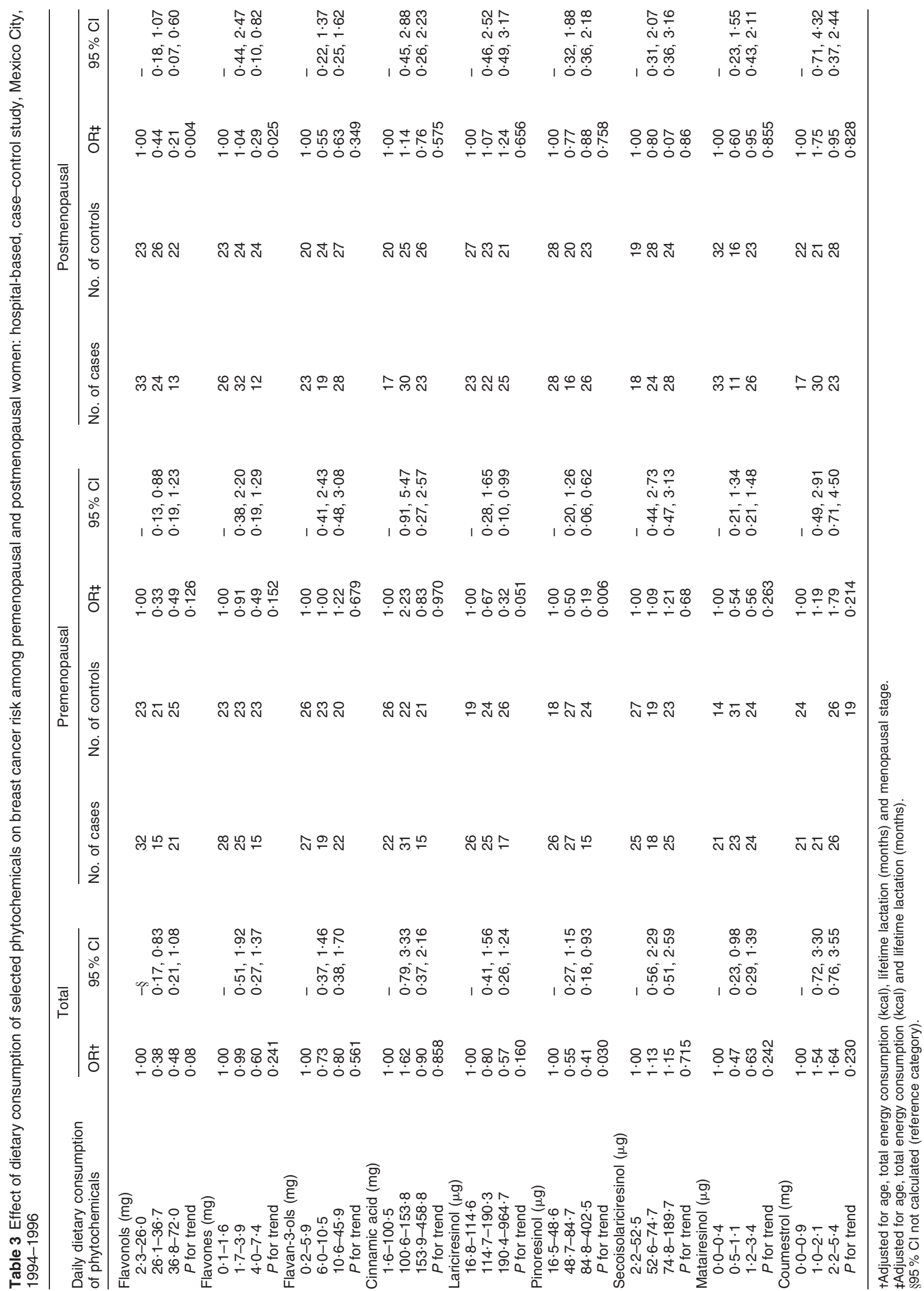


statistics show that around $20 \%$ of women are OC users, there is no reason to consider an association between OC and/or HRT and phytochemical consumption that could bias our results ${ }^{(39)}$.

In Mexico the age-adjusted incidence rate of $\mathrm{BC}$ is four times smaller than that reported in the USA $(26 \cdot 4 v \cdot 101 \cdot 1$ per 100000$)^{(40)}$. In the USA the incidence rate of BC among states does not significantly vary ${ }^{(41)}$, whereas in Mexico large differences exist by region. The northern frontier states of Mexico have $\mathrm{BC}$ incidence rate similar to the USA and approximately three to four times greater than that observed in the southern zone of the country ${ }^{(42)}$. While many factors could explain this difference, it is important to note that dietary patterns observed in both regions are quite different ${ }^{(43)}$. The diet in the southern and central region of Mexico is characterized as being lower in fat and red meats, but rich in foods that are high in flavones and lignans (e.g. corn, beans and green vegetables). The diet in the northern region is more similar to the US diet, characterized by a high consumption of fats, sugars and red meats, and a low consumption of vegetables. Although the previous perspective is ecological, it is consistent with our results.

Dietary phytochemical consumption could play an important protective role in BC development, as well as in the differences in $\mathrm{BC}$ incidence observed among regions in Mexico. Several phytochemical food sources and types of phytochemicals across the world should be considered for evaluation in future studies.

\section{Acknowledgements}

Study design and collection of information were financed by Consejo Nacional de Ciencia y Tecnología de México (CONACyT). Funding from the Fogarty International Center of the National Institutes of Health (D43TW00640) to Mount Sinai School of Medicine/Queens College International Training and Research in Environmental and Occupational Health Program financed the collection, analysis and interpretation of data, as well as writing of the manuscript. The authors declare that they have no competing interests.

Authors' contributions: L.T.-S. participated in statistical analysis planning and writing the manuscript. M.G.-P. performed the statistical analysis of data and collaborated in writing the manuscript. M.S.W. participated in study design, exposure estimations and critical revisions of the manuscript. L.L.-C. conceptualized the study, obtained the funds for the study and made critical revisions of the manuscript.

\section{References}

1. Manach C, Scalbert A, Morand C, Remesey C \& Jiménez L (2004) Polyphenols: food sources and bioavailability. Am J Clin Nutr 79, 727-747.

2. Webb A \& McCullough M (2005) Dietary lignans potential role in cancer prevention. Nutr Cancer 51, 117-131.
3. World Cancer Research Fund \& American Institute for Cancer Research (1997) Food, Nutrition and the Prevention of Cancer: A Global Perspective. Washington, DC: AICR.

4. Yamamoto S, Soube T, Kobayashi M, Sasaki S \& Tsugane S; Japan Public Health Center-Based Prospective Study on Cancer Cardiovascular Diseases Group (2003) Soy, isoflavones, and breast cancer risk in Japan. J Natl Cancer Inst 95, 906-913.

5. Shu XO, Jin F, Dai Q, Wen W, Potter JD, Kushi LH, Ruan Z, Gao YT \& Zheng W (2001) Soyfood intake during adolescence and subsequent risk of breast cancer among Chinese women. Cancer Epidemiol Biomarkers Prev 10, 483-488.

6. Zheng W, Dai Q, Custer LJ, Shu XO, Wen WQ, Jin F \& Franke AA (1999) Urinary excretion of isoflavonoids and the risk of breast cancer. Cancer Epidemiol Biomarkers Prev 8, 35-40.

7. Dai Q, Franke AA, Jin F, Shu XO, Hebert JR, Custer LJ, Cheng J, Gao YT \& Zheng W (2002) Urinary excretion of phytoestrogens and risk of breast cancer among Chinese women in Shanghai. Cancer Epidemiol Biomarkers Prev 11, 815-821.

8. Keinan-Boker L, van Der Schouw YT, Grobbee DE \& Peeters PH (2004) Dietary phytoestrogens and breast cancer risk. Am J Clin Nutr 79, 282-288.

9. Adebamowo CA, Cho E, Sampson L, Katan MB, Spiegelman D, Willett WC \& Holmes MD (2005) Dietary flavonols and flavonol-rich foods intake and the risk of breast cancer. Int J Cancer 114, 628-633.

10. Horn-Ross PL, John EM, Lee M, Stewart SL, Koo J, Sakoda LC, Shiau AC, Goldstein J, Davis P \& Perez-Stable EJ (2001) Phytoestrogen consumption and breast cancer risk in a multiethnic population: the Bay Area Breast Cancer Study. Am J Epidemiol 154, 434-441.

11. Horn-Ross PL, Hoggatt KJ, West DW et al. (2002) Recent diet and breast cancer risk: the California Teachers Study (USA). Cancer Causes Control 13, 407-415.

12. den Tonkelaar I, Keinan-Boker L, Veer PV, Arts CJM, Adlercreutz H, Thijssen JHH \& Peeters PHM (2001) Urinary phytoestrogens and postmenopausal breast cancer risk. Cancer Epidemiol Biomarkers Prev 10, 223-228.

13. Peterson J, Lagiou P, Samoli E, Lagiou A, Katsouyanni K, La Vecchia C, Dwyer J \& Trichopoulos D (2003) Flavonoid intake and breast cancer risk: a case-control study in Greece. Br J Cancer 89, 1255-1259.

14. Bosetti C, Spertini L, Parpinel M et al. (2005) Flavonoids and breast cancer risk in Italy. Cancer Epidemiol Biomarkers Prev 14, 805-808.

15. Fink BN, Steck SE, Wolff MS et al. (2007) Dietary flavonoid intake and breast cancer risk among women on Long Island. Am J Epidemiol 165, 514-523.

16. Linseisen J, Piller R, Hermann S \& Chang-Claude J; German Case-Control Study (2004) Dietary phytoestrogen intake and premenopausal breast cancer risk in a German case-control study. Int J Cancer 110, 284-290.

17. Murkies A, Dalais FS, Briganti EM, Burger HG, Healy DL, Wahlqvist ML \& Davis SR (2000) Phytoestrogens and breast cancer in postmenopausal women: a case control study. Menopause 7, 289-296.

18. McCann SE, Muti P, Vito D, Edge SB, Trevisan M \& Freudenheim J (2004) Dietary lignan intake and risk of preand postmenopausal breast cancer. Int J Cancer 111, 440-443.

19. Piller R, Chang-Claude J \& Linseisen J (2006) Plasma enterolactone and genistein and the risk of premenopausal breast cancer. Eur J Cancer Prev 15, 225-232.

20. Hulten K, Winkvist A, Lenner P, Johansson R, Adlercreutz H \& Hallmans G (2002) An incident case-referent study on plasma enterolactone and breast cancer risk. Eur J Nutr $\mathbf{4 1}$, 168-176. 
21. Ingram D, Sanders K, Kolybaba M \& Lopez D (1997) Case-control study of phyto-oestrogens and breast cancer. Lancet 350, 990-994.

22. Torres Sánchez L, López Carrillo L, López Cervantes M, Rueda C \& Wolff M (2000) Food sources of phytoestrogens and breast cancer risk in Mexican women. Nutr Cancer 37, 16-21.

23. Bonilla-Fernandez P, Lopez-Cervantes M, Torres-Sanchez LE, Tortolero-Luna G \& Lopez-Carrillo L (2003) Nutritional factors and breast cancer in Mexico. Nutr Cancer 45 , $148-155$.

24. Lajous M, Lazcano-Ponce E, Hernandez-Avila M, Willett W \& Romieu I (2006) Folate, vitamin B(6), and vitamin B(12) intake and the risk of breast cancer among Mexican women. Cancer Epidemiol Biomarkers Prev 15, 443-448.

25. Romieu I, Lazcano-Ponce E, Sanchez-Zamorano LM, Willett W \& Hernandez-Avila M (2004) Carbohydrates and the risk of breast cancer among Mexican women. Cancer Epidemiol Biomarkers Prev 13, 1283-1289.

26. Galvan-Portillo M, Wolff MS, Torres-Sanchez L, LopezCervantes M \& Lopez-Carrillo L (2007) Phytoestrogen contents in Mexican foods. Salud Publica Mex $\mathbf{4 9}$, 126-131.

27. Lopez-Carrillo L, Blair A, Lopez-Cervantes M, Cebrian M, Rueda C, Reyes R, Mohar A \& Bravo J (1997) Dichlorodiphenyltrichloroethane serum levels and breast cancer risk: a case-control study from Mexico. Cancer Res 57, 3728-3732.

28. Greenland S (1989) Modeling and variable selection in epidemiologic analysis. Am J Public Health 79, 340-349.

29. Touillaud MS, Thiébaut AC, Fournier A, Niravong M, Boutron-Ruault MC \& Clavel-Chapelon F (2007) Dietary lignan intake and postmenopausal breast cancer risk by estrogen and progesterone receptor status. J Natl Cancer Inst 99, 475-486.

30. Mueller SO, Simon S, Chae K, Metzler M \& Korach KS (2004) Phytoestrogens and their human metabolites show distinct agonistic and antagonistic properties on estrogen receptor $\alpha(\mathrm{ER} \alpha)$ and ER $\beta$ in human cells. Toxicol Sci 80, 14-25.

31. Arnault I \& Auger J (2006) Seleno-compounds in garlic and onion. J Chromatogr A 1112, 23-30.

32. Mizushina Y, Nakanishi R, Kuriyama I et al. (2006) $\beta$-Sitosterol-3-O- $\beta$-D-glucopyranoside: a eukaryotic DNA polymerase $\lambda$ inhibitor. I Steroid Biochem Mol Biol 99, 100-107.
33. Milder I, Arts I, van de Putte B, Venema D \& Hollman P (2005) Lignan contents of Dutch plant foods: a database including lariciresinol, pinoresinol, secoisolariciresinol and matairesinol. BrJ Nutr 93, 393-402.

34. Knight DC \& Eden JA (1996) A review of the clinical effects of phytoestrogens. Obstet Gynecol 87, 897-904.

35. Adlercreutz H (2002) Phytoestrogens and breast cancer. J Steroid Biochem Mol Biol 83, 113-118.

36. Low YL, Taylor JI, Grace PB et al. (2005) Phytoestrogen exposure correlation with plasma estradiol in postmenopausal women in European Prospective Investigation of Cancer and Nutrition-Norfolk may involve diet-gene interactions. Cancer Epidemiol Biomarkers Prev 14, 213-220.

37. Olsen A, Knudsen KE, Thomsen BL, Loft S, Stripp C, Overvad K, Moller S \& Tjonneland A (2004) Plasma enterolactone and breast cancer incidence by estrogen receptor status. Cancer Epidemiol Biomarkers Prev 13, 2084-2089.

38. Rivera Dommarco J, Shamah Levy T, Villalpando Hernández S, González de Cossio T, Hernández Prado B \& Sepúlveda J (2001) Estado nutricio de mujeres y niños en México. In Encuesta Nacional de Nutrición 1999, pp. 114-116. Cuernavaca: Instituto Nacional de Salud Pública.

39. Secretaría de Salud (1999) Encuesta Nacional sobre Fecundidad y Salud (Enfes), 1987. México, DF: Secretaría de Salud.

40. Ferlay J, Bray F, Pisani P \& Parkin DM (2004) GLOBOCAN 2002: Cancer Incidence, Mortality and Prevalence Worldwide. IARC Cancer Base no. 5, version 2.0. Lyon: IARC Press.

41. Jemal A, Siegel R, Ward E, Murray T, Xu J, Smigal C \& Thun MJ (2006) Cancer statistics, 2006. CA Cancer J Clin 56, 106-130.

42. Secretaria de Salud (2002) Compendio de Cáncer 2002. Registro Histopatológico de Neoplasias Malignas. México, DF: Subsecretaría de Prevención y Promoción de la Salud, Centro Nacional de Vigilancia Epidemiológica y Control de Enfermedades, Dirección General de Epidemiología.

43. Barquera S, Hotz C, Rivera J, Tolentino L, Espinoza J, Campos I \& Shamah T (2006) Food consumption, food expenditure, anthropometric status and nutritionrelated diseases in Mexico. In The Double Burden of Malnutrition, Case Studies from Six Developing Countries, pp. 161-203. FAO Food and Nutrition Paper no. 84. Rome: FAO. 